\title{
Schemes, Critical Questions, and Complete Argument Evaluation
}

\author{
Shiyang Yu' ${ }^{1} \cdot$ Frank Zenker ${ }^{2}[$
}

Published online: 6 March 2020

(c) The Author(s) 2020

\begin{abstract}
According to the argument scheme approach, to evaluate a given scheme-saturating instance completely does entail asking all critical questions (CQs) relevant to it. Although this is a central task for argumentation theorists, the field currently lacks a method for providing a complete argument evaluation. Approaching this task at the meta-level, we combine a logical with a substantive approach to the argument schemes by starting from Toulmin's schema: 'data, warrant, so claim'. For the yet more general schema: 'premise(s); if premise(s), then conclusion; so conclusion', we forward a meta-level CQ-list that is arguably both complete and applicable. This list should inform ongoing theoretical efforts at generating appropriate object-level CQs for specific argument schemes.
\end{abstract}

Keywords Argument - Complete evaluation · Critical question · Scheme · Standardization

\section{Introduction}

For the purpose of evaluating natural language arguments, argument(ation) schemes and their associated critical questions (CQs) have remained central to contemporary argumentation theory (e.g., Walton et al. 2014, 89). Probably the first scholar to use 'critical question' (CQ) in today's technical sense was Hastings (1962). Yet earlier,

Frank Zenker

f.zenker@ans.pw.edu.pl

1 College of Philosophy, Nankai University, Tianjin, People's Republic of China

2 Center for Formal Ontology, Warsaw University of Technology, Pl. Politechniki 1, 00-661 Warsaw, Poland 
Perelman and Olbrechts-Tyteca (1958) had introduced 'argumentative scheme' (French: schème argumentatif) with reference to the schemes' historical ancestors: the topoi (Greek: places; Latin: loci). ${ }^{1}$ While the topoi serve primarily in argument construction, whereas the schemes and CQs serve primarily in argument evaluation, both concepts, of course, are closely related. Even when restricted to argument evaluation, however, a unified theoretical understanding of argument schemes and CQs has so far remained absent.

Indeed, already a unified taxonomy of argument schemes can hardly arise as long as "existing classifications of arguments are unsatisfying in a number of ways" (Wagemans 2016, 1). ${ }^{2}$ For instance, pragma-dialecticians treat an argument scheme as a kind of "characteriz[ation] [of] the way in which the reason given in support of a standpoint is supposed to bring about a transfer of acceptance to the standpoint in a particular type of argumentation" (van Eemeren 2018, 7). Further, informal logicians and scholars in AI \& law tend to view schemes as "forms of argument (structures of inference) that represent structures of common types of arguments used in everyday discourse, as well as in special contexts like those of legal argumentation and scientific argumentation" (Walton et al. 2008, 1). Virtually all scholars, moreover, let 'argument scheme' denote a linguistic structure, while some few also view such structures as externalizing an (internal) reasoning scheme (Blair 2001; Hitchcock 2006, 218). ${ }^{3}$ We adopt the former use.

Schemes and CQs clearly relate to other methods for evaluating arguments. For example, a normative application of fallacy theory assumes that "many [possibly most] of the fallacies are failed instances of good argument schemes or forms" (Tindale 2007, xiv), although such instances as “[a] 'Straw Man' argument would seem to be always incorrect and have no redeemable instances" (ibid., 12). Argument schemes also are indispensable in computational versions of acceptance-based approaches like Walton (2016), who-viewing schemes and CQs as basic (ibid., 339)_finds them compatible with probabilistic approaches like Verheij's (2014). Hahn and Hornikx $(2016,1833)$ even argue "that the most fruitful approach to developing normative models of argument quality [...] combines the argumentation scheme approach with [the Pascalian probability approach known as] Bayesian argumentation."

\footnotetext{
1 For additional background, see Garssen's (2001) historical overview, Rubinelli (2009) on Aristotle's and Cicero's topoi, Rapp and Wagner (2013, 22-24) on how the topoi relate to argument schemes, and Walton et al. (2008) for a collection of schemes and associated CQs.

2 Wagemans' own periodic table of arguments is based on three distinctions (ibid., 3-7): subject argument versus predicate argument, a distinction referencing the constituents of arguments under a formallinguistic analysis; first-order versus second-order argument, a distinction seemingly running parallel to the classical one between internal and external topics (Hitchcock and Wagemans 2011, 197-199); and finally the distinction-originating in debate theory-between propositions that constitute policy-, value-, or fact-related argumentation (Schut and Wagemans 2014, 25-39).

3 Argument tends to differ from reasoning in its direction. Argument runs typically (but not necessarily) from a claim to its supporting reason(s), whereas reasoning runs from the reason(s) to a claim. Only the former direction assumes that a claim is yet in need of reasoned support. In fact, the argument-to-reasoning relation is yet more complex: "[a]rguments can also [...] stimulate reflection on one's own reasoning," which is one of their "cognitive functions" (Hoffmann 2016, 366).
} 
Contemporary scholarship associates lists of CQs (or CQ-lists) for the most part to the schemes themselves, and only in rare cases to their applied instances. This association occurs at what we call the theoretical level, respectively the applied level. At both levels, however, agreed-upon stopping criteria for a complete CQ-list are unavailable, thus leaving it unclear whether analysts must ask yet further CQs. Our main objective in this paper, therefore, is to develop meta-level conditions under which a CQ-based evaluation is complete. Similar in motivation is Rigotti and Greco Morasso's $(2006,2009,2010)$ argumentum model of topics (AMT). ${ }^{4}$ Closest to our own approach probably comes the epistemological approach of Lumer (2011), who treats an argument scheme as the "general form of an ideal, elementary or molecular argument" (ibid., 8), and considers "the whole system of (ideal [i.e., fully explicit, valid]) elementary argument schemes [as] the argument tree" (ibid., 10; his italics). This tree's three "branches [should] be defined [...] according to the argument schemes' epistemological underpinnings," namely: "logic, probability theory and (prudential) desirability theory" (ibid., 10), which thus serve as meta-level evaluative principles. Our approach differs from Lumer's in that we treat ARGUMENT SCHEME as a primarily logical concept. ${ }^{5}$ Moreover, Lumer seems to downplay the influence of the Aristotelian Topics (ibid., 2), whereas our own attempt seeks to incorporate them by enriching a logical with a substantive approach.

The following thus offers a meta-level hybrid-account of argument schemes and CQs, that is, a logical account (Sect. 2) complemented by a substantive account (Sect. 3). We submit that the Toulmin model proves sufficient to develop this account (Sect. 4). Upon reviewing related work (Sect. 5), we propose a complete CQ-list, justify its applicability (Sect. 6), and then conclude (Sect. 7).

\section{Why a Logical Account of Argument Schemes?}

\subsection{Levels}

One may associate CQs to an argument scheme or to its specific instance. The former level we call theoretical because it abstracts from the argument's specific content; the latter level we call applied. Accordingly, one may separate theoretical from applied CQs, which specify the theoretical CQs by saturating their placeholders.

\footnotetext{
${ }^{4}$ Devised for argument reconstruction, the AMT builds upon the pragma-dialectical distinction between procedural and material starting points. According to the AMT, an "argument scheme combines a procedural starting point, coinciding with the inferential connection (maxim) that is activated, with a material starting point guaranteeing [...] the applicability of the maxim to the actual situation considered in the argument" (Rigotti and Greco Morasso 2010, 493). Regarding the procedural starting point, they distinguish three levels: (i) ontological relations, represented as locus; (ii) a series of inferential connections ('maxims') arising from each ontological relation; and (iii) a logical form activated by each maxim. Our own approach is more fundamental because our theoretical level can house all of their three levels.

5 We borrow the term 'logical' from Prakken (2010), who obtains a logical account by formalizing argument schemes such that 'formalization' denotes his method, while 'logical account' names the method's outcome. As an anonymous reviewer has rightly pointed out, one may alternatively call our account 'formal' rather than 'logical'.
} 
This distinction also applies to argument schemes. As an example, consider the 'from a position to know'-scheme at the theoretical level (1a-c), ${ }^{6}$ and compare three of its instances at the applied level $\left(1 \mathrm{a}^{\prime}-\mathrm{c}^{\prime}\right)$, where substantive rather than logical information saturates the placeholders $a$ and $A$.

(1a) Argument scheme 'from a position to know'; theoretical level, instance 1 $a$ is in a position to know whether $A$ is true.

$a$ asserts that $A$ is true.

$A$ is true.

(1b) Argument scheme 'from a position to know'; theoretical level, instance 2 $a$ is in a position to know whether $A$ is true.

$a$ asserts that $A$ is true.

If $a$ is in a position to know whether $A$ is true, and $a$ asserts that $A$ is true, then $A$ is true.

$A$ is true.

(1c) Argument scheme 'from a position to know'; theoretical level, instance 3 $a$ is in a position to know whether $A$ is true.

$a$ asserts that $A$ is true.

$a$ is an honest (trustworthy, reliable) source.

$A$ is true.

(1a') Argument scheme 'from a position to know'; applied level, instance 1 Harry is in a position to know whether 'Mary is the murderer' is true. Harry asserts, "Mary is the murderer' is true."7

'Mary is the murderer' is true.

\footnotetext{
${ }^{6}$ See Prakken (2010) and our Sect. 2.2 for alternative scheme-versions, whose names variously carry 'a', 'the' or no article), and the wording of which is always a matter of choice. Walton et al. $(2008,309)$, for instance, list this scheme as "Major Premise: Source $a$ is in position to know about things in a certain subject domain $S$ containing proposition A. Minor Premise: $a$ asserts that $A$ is true (false). Conclusion: $A$ is true (false).".

${ }^{7}$ At the applied level, one may find the alternative version: "Harry asserts 'Mary is the murderer'." Following a deflationary account of truth, this version omits 'is true' (e.g., Daniel and Nic 2014). Yet both versions amount to pragmatic (near-)equivalents.
} 
(1b') Argument scheme 'from a position to know'; applied level, instance 2 Harry is in a position to know whether 'Mary is the murderer' is true. Harry asserts, "'Mary is the murderer' is true."

If Harry is in a position to know whether 'Mary is the murderer' is true, and Harry asserts 'Mary is the murderer', then 'Mary is the murderer' is true. 'Mary is the murderer' is true.

(1c') Argument scheme 'from a position to know'; applied level, instance 3 Harry is in a position to know whether 'Mary is the murderer' is true. Harry asserts " "Mary is the murderer' is true."

Harry is an honest (trustworthy, reliable) source.

'Mary is the murderer' is true.

As these examples show, at the applied level one simply replaces ' $a$ ' by 'Harry', and ' $A$ ' by 'Mary is the murderer'. At the theoretical level, moreover, 1(b) externalizes the logical inference underlying 1(a). Finally, 1(c') states information-viz. Harry is an honest (trustworthy, reliable) source-that, if it is false, expresses exceptions to the inference in $1\left(b^{\prime}\right)$, as do $(1 b-1 c)$. (We return to this in Sect. 2.2).

Evaluating a given scheme instance requires a general normative yardstick, one not limited to specific schemes or instances. Only if the theoretical level provides such normativity, or reasonableness, can this normativity transfer unproblematically from the theoretical to the applied level. This constraint forces us to recognize a third level: the meta-level. Its instances are the logical forms $\left(1 \mathrm{a}^{\prime \prime}-\mathrm{c}^{\prime \prime}\right)$, which are themselves yet more abstract than the instances at the theoretical level. As desired, these meta-level logical forms are sufficiently general to transfer their own evident reasonableness from the meta-level to the theoretical level.

(1a") Argument scheme 'from a position to know'; meta-level, instance 1 Premise(s)

Conclusion

$\left(1 b^{\prime \prime}\right)$ Argument scheme 'from a position to know'; meta-level, instance 2 Premise(s)

If premise(s), then conclusion

Conclusion 
(1c") Argument scheme 'from a position to know'; meta-level, instance 3

Premise(s)

Absence of exception(s)

Conclusion

Insofar as the meta-level is a logical construction, one must accordingly treat an argument scheme as a logical structure. This structure one can study independently of dialectical or rhetorical considerations, because such considerations will affect neither a scheme's structure nor its components. They rather pertain to the criteria for evaluating a scheme instance, for instance with regard to being internally consistent, audience-accepted, commitment-incurring, burden-of-proof discharging, etc. (see Sect. 6.2).

\subsection{A Logical Account of Argument Schemes}

The two basic features of our account thus are an inference rule and exceptions to it. Argument schemes, after all, "can be transformed into instances of logical inference rules by adding the connection between premises and conclusion as a conditional premise" (Prakken 2005, 307; see Walton 1996, 2016, 323-325). Treating schemes as logical constructs therefore entails that "a procedure for evaluating arguments primarily takes the form of a [non-monotonic] logic" (Prakken 2010, 1). ${ }^{8}$

For instance, the inference rule in (2)-containing 'usually'-is the defeasible modus ponens rule.

\section{Defeasible modus ponens rule \\ $P$ \\ If $P$ then usually $Q$ \\ Therefore (presumably), $Q$}

Saturating (2) to the 'from a position to know'-scheme can either yield (3), containing a defeasible inference rule, or (4), containing a generalised conditional premise that must itself be defeasible (Prakken 2010, 7f.). The choice between (3) and (4), of course, is a matter of taste rather than of substance.

\footnotetext{
${ }^{8}$ Prakken $(2010,5)$ submits that a scheme not only includes "defeasible inference rules, i.e., elements of a reasoning method." He rather finds that a scheme can be "a reasoning method in itself" (ibid.), because it features "abstractions of more complex lines of reasoning, which may not always be naturally reduced to reasoning with defeasible inference rules" (ibid., 13). What thus amounts to an identification of the method with its elements, he illustrates with the modern version of Peirce's abductive reasoning (Yu and Zenker 2018) — an identification we reject. For it raises questions (e.g., "How many reasoning methods are there; what separates them?") that Prakken himself leaves unaddressed.
} 
(3) Argument scheme 'from a position to know'; defeasible inference rule $a$ is in a position to know whether $A$ is true.

$a$ asserts that $A$ is true.

$A$ is true.

(4) Argument scheme 'from a position to know'; generalised conditional premise $a$ is in a position to know whether $A$ is true.

$a$ asserts that $A$ is true.

If $a$ is in a position to know if $A$ is true, and $a$ asserts that $A$ is true, then $A$ is true.

$A$ is true.

When formulating the inference rule, another matter of taste is whether to include a dedicated premise stating the absence of exceptions, ${ }^{9}$ as in (5).

(5) Argument scheme 'from a position to know'; inference-rule account with exception-premise(s)

$a$ is in a position to know whether $A$ is true.

$a$ asserts that $A$ is true.

$a$ is an honest (trustworthy, reliable) source.

$A$ is true.

Moving beyond considerations of mere taste, evaluating a defeasible argument completely always presupposes that one makes its implicit parts explicit (Ennis 1982, 66; Gough and Tindale 1985, 99; van Eemeren and Grootendorst 1992, 141; Yu and Zenker 2019). At the applied level, this demands listing an inference's exceptions. At the same time, however, it is unclear whether all actual and possible exceptions can be listed (Zenker 2009). Even if all premises of (5) are true, for instance, one cannot safely infer ' $A$ is true', because $a$ might lie. To give another example, the premise ' $a$ is generally a reliable source' does not imply ' $a$ speaks the truth now'. Otherwise, one could deduce ' $A$ is true' from ' $a$ is generally a reliable source' and ' $a$ asserts that $A$ ' alone. (As this sidesteps the premise ' $a$ is in a position to know whether $A$ is true', however, it also makes it questionable that one treats the 'from a position to know'-scheme.) The gap in meaning between 'generally' and 'now' thus implies implicit parts, which to make explicit is an unsatisfied need that rightly fosters doubt whether a list of applied CQs can ever be complete (see note 9).

\footnotetext{
${ }^{9}$ For any scheme, adding inference-invalidating exceptions to the premises turns undercutting attacksdirected at the inference in (3) - into premise attacks in (5), for one can always transform a scheme's CQs into additional premises (Prakken 2010, 9; Hoffmann 2018, 233). Logically equivalent, both methods differ in convenience.
} 
In developing a logical account that fits with any argument scheme, the forgoing provides strong reasons against operating at the applied level. Instead, we opt for a meta-level version of a defeasible conditional premise, as in (6).

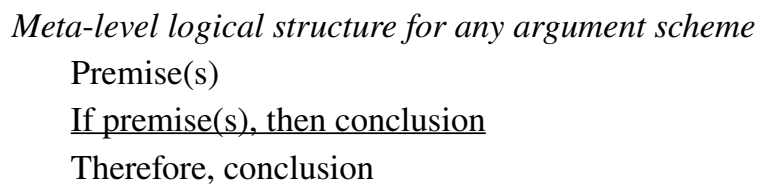

As (6) abstracts from (2), one may omit 'usually' (contained in the 'if-then' conditional's saturated version), because this term becomes redundant at the meta-level. An argument scheme's logical structure now looks deductive. Far from providing clarity, however, a deductive structure rather obscures the conditional's defeasible character that the 'if-then' premise expresses, one that pivots on substantive rather than logical information. We therefore proceed to complement our logical account with a substantive account.

\section{A Substantive Account of Argument Schemes}

\subsection{The Pragma-Dialectical Theory}

Pragma-dialecticians view argumentation as "a verbal, social, and rational activity aimed at convincing a reasonable critic of the acceptability of a standpoint by putting forward a constellation of propositions justifying or refuting the proposition expressed in the standpoint" (van Eemeren and Grootendorst 2004, 1). As the authors rightly note, logic alone offers but limited insights into how the acceptability of an argument's premises transfers to a claim. For such transfers "to achieve the interactional effect that the listener accept[s] [the speaker's] standpoint," speakers rely not on logic but rather "on a ready-made argumentation scheme"-or argument scheme-that is, "a more or less conventionalized way of representing the relation between what is stated in the argument and what is stated in the standpoint" (van Eemeren and Grootendorst 1992, 96; their italics).

Argument schemes thus represent kinds of relations between premises, or reasons, and a standpoint, or claim. As the theory's basic kinds, moreover, Pragmadialecticians distinguish relations based on symptomaticity, similarity, or causality (Garssen 1994, 1997). As an example, if "someone tries to convince his interlocutor by pointing out that something is symptomatic of something else," then acceptability is transferred by "a relation of concomitance" (van Eemeren and Grootendorst 1992, 96f.). In such cases, "[t]he argumentation is presented as if it [were] an expression, a phenomenon, a sign or some other kind of symptom of what is stated in the standpoint" (ibid., 97). As is the case with the other two kinds, this relation cites substantive rather than formal content. 


\subsection{A Substantive Account's Benefits}

As a logical premise, the 'if-then' premise is central to both deductive inferences such as modus ponens, as well as to inductive ones such as the statistical syllogism. Insofar as the three basic relations specify the 'if-then' premise's substance, moreover, suitable replacement in (6) yields:

\section{(7) Combined argument scheme at the meta-level}

Premise(s).

The relation $R$ holds between the referents of premise(s) and conclusion. Therefore, conclusion.

This specifies what the 'if-then' premise means. Like a logical account, also a substantive account allows one to distinguish three levels. Given the similarity relation, for instance, one can readily obtain three increasingly abstract specifications:

(8a) Example, similarity relation, applied level

"The method I propose worked last year (and this problem is similar to last year's), so the method will work again." (van Eemeren and Grootendorst 1992, 97)

(8b) Example, similarity relation, theoretical level

"For [problem] $X$, [method] $Y$ is valid because [, f]or [problem] $Z$, [method] $Y$ is valid and $X$ is comparable [because it is relevantly similar] to $Z$." (van Eemeren and Kruiger 1987, 73f.)

(8c) Example, similarity relation, meta-level

For $X, Y$ is valid because, for $Z, Y$ is valid; and the relation $R$ connects $X$ and $Z$.

In (8a), the similarity between last year's and this year's problem shall support that the method is valid for this year's problem, a conclusion that is grounded in the method's proven validity for a similar problem. Strictly speaking, if the acceptability-grounding similarity relation, $R$, holds true, it cannot in any good sense hold between (parts of) premises and the conclusion, but must rather hold between the two problems, on one hand, and between the methods' validity for each problem, on 
the other. ${ }^{10}$ Of course, where the distinction between the linguistic and the onticbetween words and things - is negligible, one may abstract $R$ yet further:

(9a) Example, similarity relation, applied level

The method I propose worked last year (and the method's proven problemsolving ability for last year's problem is similar to the method's problemsolving validity for this year's problem, because the problems are similar), so the method will work again.

(9b) Example, similarity relation, theoretical level

Premise(s).

Therefore, conclusion.

\section{(9c) General relation, meta-level}

Premise(s).

Therefore, conclusion.

Like the meta-level treatment of the 'from a position to know'-scheme in $\left(1 a^{\prime \prime}-c^{\prime \prime}\right),{ }^{11}(9 c)$ abstracts fully from the relation being one of similarity. It is this scheme, therefore, that applies to all types of substantive relations. Having thus represented an argument scheme's structure, we can turn to its substantive aspect.

\subsection{Defining Argument Scheme}

A consensus-definition of 'argument scheme' being absent, our own definition pivots on three choices. These relate to the level of abstraction, to the substantive versus logical distinction, and to the object of study. First, we define 'argument scheme' at the meta-level, to which both the theoretical and the object level are subordinate. The 'argument from a position to know'-scheme, for instance, exemplifies the concept

\footnotetext{
10 As Wagemans $(2019,61)$ observes, "the common term [that is shared between the premises] functions as the fulcrum of the leverage of acceptability from the premise to the conclusion." A transfer of acceptability that is itself achieved through speakers' use of natural language argument will trivially depend on linguistic information. The transfer's own reasonableness, however, may non-trivially depend on ontic information, viz. on how the world is. This holds although — on the linguistic side —one can distinguish, at the same abstract level, two additional similarity-levels. In 8(a), at one level, a similarity relation holds between the entire premise and the conclusion-viz. between 'the method's problem-solving validity for last year's problem' and 'the method's problem-solving validity for this year's problem'. At a second level, an additional similarity relation holds between this year's and last year's problem, now treated as parts of the premise and the conclusion. (We thank an anonymous reviewer for this observation.).

11 One can alternatively treat the 'from a position to know'-scheme as in (7). Considering the witness as an authority lets the scheme feature a symptomatic relation (Garssen 2001, 92).
} 
ARGUMENT SCHEME, yet the scheme itself remains distinct from the concept. ${ }^{12}$ Second, argument schemes do not merely cite substantive information that a logical account abstracts "away," they also cite such information at structural positions that a logical account helps identify. A logical and a substantive account are therefore complementary. Third, if one were to define an argument scheme at the meta-level in terms of the substantive relation alone, then one would capture merely the 'if-then' premise. However, one could obviously not saturate this scheme any further to (re-) construct an argument at the applied-level. We therefore define as follows:

Definition of 'argument scheme': $S$ is an argument scheme if, and only if, $S$ is a meta-level argument with at least one premise and a conclusion, where the transfer of the premise(s)'s acceptability to the conclusion grounds in a substantive-as opposed to a logical—relation, $R$, that holds between the scheme's sentences, their parts, or their referents.

This captures the combined meta-level account of argument scheme in (7). We view (7) as embodying an argument scheme's structure and its substance. Having thus defined the noumenon of argument scheme, we can turn to its evaluation, a task for which the Toulmin model proves sufficient.

\section{Argument Evaluation on the Toulmin Model}

\subsection{The Toulmin Model}

Viewing arguments as organisms, Toulmin (1958 [2003]) ${ }^{13}$ observed that different fields use distinct argument evaluation criteria, but the same argument layout, or model (Conley 1990, 294-296; Hitchcock and Verheij 2006; van Eemeren et al. 2014, 203-256; Zenker 2018). In fact, Toulmin's model became so influential as to widely "replace the old concepts of 'premises' and 'conclusion' with the new concepts of 'claim', 'data', 'warrant', 'model qualifier', 'rebuttal' and 'backing"' (van Eemeren et al. 2014, 204). Figure 1 illustrates this model with what probably is Toulmin's best-known example (Toulmin 2003, 97).

In Fig. 1, the starting point is the claim (C) 'Harry is a British subject'; the data element (D) is 'Harry was born in Bermuda' (see ibid., 90). The warrant (W) - the relevant instance of any "general, hypothetical statements, which can act as bridges, and authorize the sort of step to which our specific argument commits us" (ibid., 91)_is: 'A man born in Bermuda will generally be a British subject'. Alas, this warrant "would possess neither authority nor currency" without a backing (B), which

\footnotetext{
12 By analogy, the infamous bird Tweety and its genus-penguin-both exemplify the concept BIRD. Yet both are distinct from the concept itself. The level at which one defines BIRD thus is more abstract than the level where one defines penguin or Tweety. In other words, Tweety, penguin, and BIRD are housed at the applied, the theoretical, and the meta-level.

13 Page numbers cited for Toulmin (1958) refer to Toulmin (2003).
} 


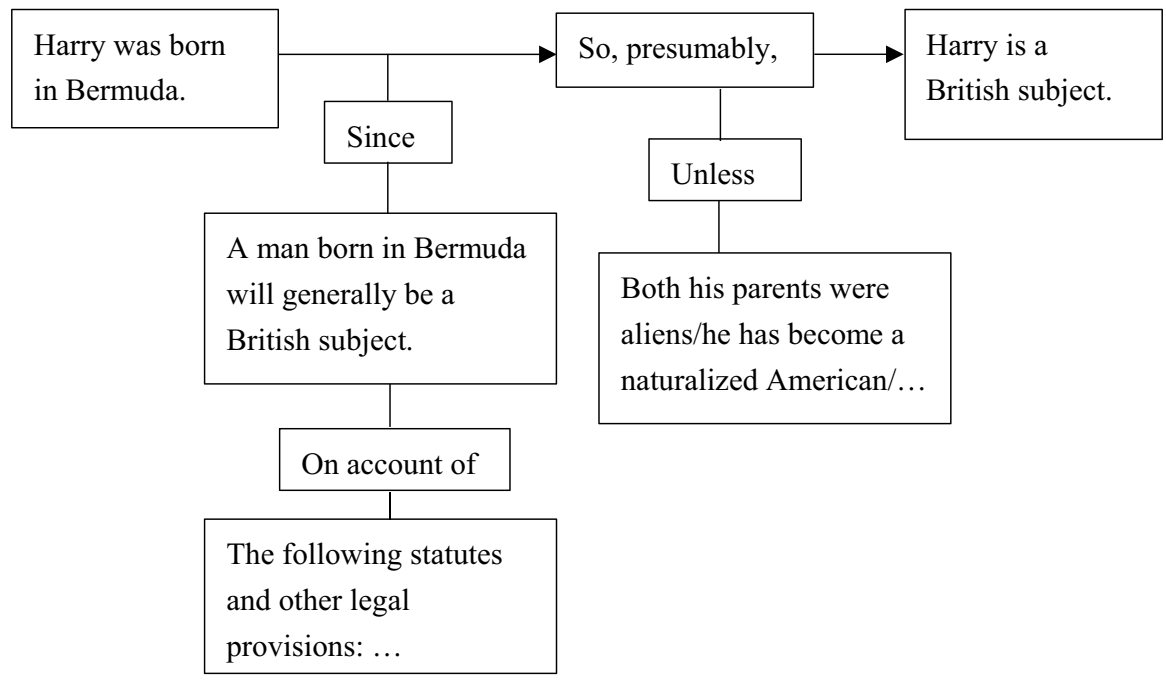

Fig. 1 Toulmin's "Harry is a British subject"-example

Toulmin abbreviates as: "[t]he following statues and other legal provisions: ..." (ibid., 96f.).

Since a warrant can feature "exceptional conditions which might be capable of defeating or rebutting the warranted conclusion," the rebuttal (R) may be instantiated, for instance, by "[b]oth his parents were aliens," or by "[h]e has become a naturalized American" (ibid., 94, 106). Accordingly, a qualifier (Q)—e.g., 'presumably'-must indicate "the strength conferred by the warrant on this step" (ibid., 94), which thus specifies the claim. We will return to this model in Sect. 4.3.

\subsection{Evaluation Criteria}

Virtually all approaches to argument evaluation seek to supply general norms. For instance, the RSA criteria-relevance, sufficiency, acceptability-demand that a good argument's premises are acceptable, relevant to the conclusion, and that they support it sufficiently (Johnson and Blair 1994, 54f.). So do Govier's (2001) ARGconditions, as well as Freeman's (1991) "basic dialectical questions [...] a rational judge would ask in drawing out an argument from a proponent" (ibid., 37f.; see his 1985, 38f.) Johnson (2000) adds premise truth as a fourth criterion, yielding the RSAT criteria. $^{14}$

The RSAT criteria are interrelated: premise sufficiency presupposes premise relevance. Both in turn presuppose premise acceptability (Biro and Siegel 1992;

\footnotetext{
14 Comparing truth to acceptability, Johnson (2000, 336f.) favors including the truth criterion, so that truth can ground acceptability (ibid., 197f.). For criticisms, see Blair (2011, 94), van Rees $(2001,236)$, van Eemeren et al. (2014, 383), and Bondy (2010).
} 
Godden and Zenker 2018), while the truth criterion may conflict with the acceptability criterion (Pinto 1994). ${ }^{15}$ In specifying how the criteria apply, Johnson (2000) suggests that for an argument to achieve rational persuasion, it is necessary (but insufficient) that, next to the argument's illative core, analysts also address its dialectical tier-for instance by asking such CQs as 'how well does the arguer deal with standard objections and criticism?'; 'how well does the argument address alternative positions, as well as its consequence or implications?' (ibid., 207f.).

Analysts may need various CQs to render the RSAT criteria applicable; yet none of the authors cited here claim that the criteria are complete. Indeed, the specification and the completeness problem-how to detail all dialectical obligations to address objections to the illative core (ibid., 327-333); are the illative core- and dialectical tier-criteria exhaustive (ibid., 333-336) - have both resisted a satisfactory solution. Rather than discuss the criteria's scope, independence, or consistency, therefore, our immediate task is to address their completeness.

\subsection{Making Toulmin's Model More Precise}

Various scholars already use the Toulmin model in argument evaluation (e.g., Freeley and Steinberg 2009; Grennan 1997; Hastings 1962; Kienpointner 1992; Toulmin et al. 1984). Particularly Verheij (2003, 2006) and Prakken (2010) use it for a complete evaluation (see Sect. 5.2). Because the model prescribes how an argument's structural parts should function, it offers a useful sense in which the model is normatively complete: an argument is good (or valid) if, and only if, all model components are fully explicit and fulfill their functions. Thus, to evaluate an argument completely is to evaluate whether all its components function well.

Some scholars have suggested equating an argument scheme with the warrant (e.g., Grennan 1997; Hitchcock 2006; see van Eemeren 2018, 171). As Marraud $(2018,325)$ observes, however, even if argument schemes are normally classified according to their warrants, nothing forces us to identify both. At any rate, this would run counter to understanding a warrant as a genuine part of an argument scheme (see Sect. 3.3).

If one instead treats only the substantive relation $R$ as a warrant, then Toulmin's model is already sufficiently general to subsume any specific argument. A decisive reason to nevertheless make the model yet more precise is Toulmin's inconsistent stance as to whether warrants must be more general than 'if $\mathrm{D}$, then $\mathrm{C}$ ' (see Hitchcock 2003, 74; and our Sect. 5.2). In addressing this question, we now turn to the three central components of Toulmin's model: warrant, backing, and qualifier.

\footnotetext{
15 "If [...] the premises have satisfied the sufficiency criterion, then [...] they are true" (Johnson 2000, 342), suggesting this order: acceptability, relevance, truth, sufficiency (ibid., 341-343). "[T]he easiest determination," he finds, "is that of relevance" (ibid., 342), while acceptability is easier to apply than relevance or truth.
} 


\subsection{Warrant, Backing, and Qualifier}

Regarding the warrant, Toulmin $(1958,91)$ states that warrants "may normally be written very briefly (in the form 'If D, then C')." This form answers to the How do you get there-question. But the warrant is neither a kind of premise, because "a premise is that from which an argument starts"-which instead suggests "Toulmin's grounds [or data]" (Hitchcock 2003, 71)—nor is the warrant an implicit premise; it is rather "not a premise at all" (ibid., 72). Moreover, one cannot readily interpret the warrant as a specific saturation of the indicative conditional 'if D, then C'. For this "misses the generality of warrants, which is one of their key features" (ibid., 73). This keeps from always considering the warrant as an explicit 'if-then' premise.

We view the warrant as the element that expresses the argument's substantive relation. With Hitchcock (2003), we thus assume that the warrant differs functionally from the data element, and that a complete argument evaluation must make both parts explicit. ${ }^{16}$ Where the warrant 'If $\mathrm{D}$, then $\mathrm{C}$ ' is overt, then, we view it as an explicit premise, otherwise as an implicit one. (This characterization is somewhat simpler than Hitchcock's own.)

Regarding the backing, some scholars view "the relation between backing and warrant [as] the same as the relation between datum and claim" (Verheij 2006, 192). As we now explain, this equation is problematic. Toulmin treats D and B as facts, whereas he treats $\mathrm{W}$ as a rule (Toulmin 1958; esp. 90, 91, 98). Specifically, the $\mathrm{D}$-to-C inference is fact-to-claim; the $\mathrm{B}$-to-W inference is fact-to-rule. The content of $\mathrm{C}$, Toulmin left unconstrained ( $\mathrm{C}$ can be a rule or a fact), while the B-to-W inference is a context-specific transformation of the 'if-then' premise. (A transformation in opposite direction is what Goodnight $(1993,51)$ calls 'legitimation inference': the specific selection of backing material as pertinent to a context.) To appreciate the problem in equating the $\mathrm{B}-\mathrm{W}$ relation with the $\mathrm{D}-\mathrm{C}$ relation, consider the wellworn, yet instructive "Petersen is a Swede"-example (Toulmin 1958, 102):

D-W-C version

(D) Petersen is a Swede.

(W) A Swede can be taken almost certainly not to be a Roman Catholic.

So, (C) Petersen is almost certainly not a Roman Catholic.

$D-B-C$ version

(D) Petersen is a Swede.

(B) The proportion of Roman Catholics Swedes is minute.

So, (C) Petersen is almost certainly not a Roman Catholic.

\footnotetext{
${ }^{16}$ Leaving the warrant implicit indicates that Toulmin (1958) had broadly ignored argument evaluation. Only in his later textbook (Toulmin et al. 1984, esp. 46, 56) did he made the warrant explicit (see Hitchcock 2003, 71f.).
} 
In (10) and (11), warrant and backing may seem to express two distinct reasons why few Swedes are Roman Catholics, in virtue of the backing expressing "a statistical report, [while the other reason expresses] an inference-warrant" (Toulmin 1958, 102). Both reasons nevertheless converge in content. Indeed, the warrant's content ("almost certainly not property $x "$ )_-read as an inference rule-mirrors the backing's content ("population with minute proportion of property $x$-bearers") read as a factual distribution. In this sense, the warrant formulates a doxastic rule, the backing a doxastic fact. 'Doxastic' means that one believes the respective contents. (One might change 'belief' to 'commitment'.) Far from denying a backing-to-warrant inference, this identifies two ways of expressing the same state of affairs.

If the backing-to-warrant inference is simple, it may behave as the transformation between (10) and (11). Other B-to-W inferences can be far more complex. For instance, one could treat the backing as a rule's legal source and the warrant as its legal interpretation. On this very matter, however, the philosophy of law offers no consensus. In legal "hard cases," indeed, a B-to-W inference may very well trigger insufficiency, inconsistency, or indeterminacy, or raise axiological issues_regarding natural or positivistic law (Peczenik 2009, 18)—on which arguers themselves need not be coherent. So, as we transform (10) into (11), we assume that warrant and backing can be co-transformed.

The qualifier refers to "the degree of force which our data confer on our claim in virtue of our warrant" (Toulmin 1958, 93) — as in: 'Presumably, Harry is a British subject'. Some scholars treat 'presumably' as "[...] a part of the sentence that expresses the claim supported by the data" (Verheij 2006, 189). Others hold that "[a] modality[expression such as 'presumably'] is not a component either of the premises or of the conclusion of an argument[, but instead] serves to modify the claim that the premises support the conclusion" (Freeman 1985, 154; italics added). Between these two options, the following seeks to offer a midway approach.

Clearly, one may challenge the data themselves, for instance as being "fake," biased, or incomplete. Moreover, the qualifier's strength depends on the warrant's force and the probability that data are faithful to the empirical reality generating them (aka the errorrate). For instance, if $\mathrm{W}$ and $\mathrm{D}$ are independent, and if W's force without $\mathrm{D}$ is $90 \%$, and the error-rate is $10 \%$, then the warrant's force reduces from $90 \%$ to $90 \% \times 90 \%=81 \%$. So, poor data necessarily weaken the qualifier.

While this speaks for keeping the claim's content distinct from its modality, the modality shall nevertheless associate to the claim itself. Our midway approach is to combine the qualifier and the claim into a new claim. It conveys the overall strength of the transition from ' $\mathrm{D}$, and 'if $\mathrm{D}$ then $\mathrm{C}$ '”, to 'C', given $\mathrm{W}$ and $\mathrm{B}$. To distinguish this construction from Toulmin's own qualifier, call it qualifier-inside-a-claim.

In sum, the warrant is the 'if $\mathrm{D}$, then $\mathrm{C}$ '-premise that expresses the substantive relation between D and C (aka. the associated conditional; see Sect. 5.2). The B-to$\mathrm{W}$ inference transforms substantive (rather than logical) information from fact-level to rule-level. Finally, a qualifier that is a part of a claim differs from the qualifier expressing the warrant's force.

With this precisification of Toulmin's model as background, we turn to related work that informs our own CQ-list (Sect. 6). 


\section{CQs as Argument Attacks or Rebuttals}

\subsection{Three Attack Types}

Prakken $(2005,303)$ submits that "the argument-scheme approach and the way it has been employed in AI \& Law respects some of the main lessons to be learnt from Toulmin's The Uses of Argument." His own version of a complete CQ-list identifies CQs dialectically as "pointers to counterarguments" (Prakken 2005, 306; 2010, 6). His list rests on the insight that "arguments can only be attacked [either] on their premises" or "on their applications of [deductive or] defeasible inference rules" (Prakken 2010, 3; see Pollock 1987, 1995; Vreeswijk 1997; Besnard and Hunter 2008; Bondarenko et al. 1997).

A defeasible attack has two sub-types: the comparatively weaker undercutter targets the inference from premises to conclusion; the stronger rebuttal targets premises or conclusion directly. Thus, "arguments can be attacked in three ways: on their premises, on their inference and on their conclusion" (Prakken 2010, 3). The three attack-types motivate associating three kinds of CQs to a scheme, namely CQs addressing (i) "whether a premise is true, [...] [ii] whether there is an exception (undercutter) to the scheme[,] and [...] [iii] whether there is an argument with a contradictory conclusion (rebuttal)" (ibid., 8f.). Because the three attack-types assign a distinct role to each $\mathrm{CQ}$, call this the three role $C Q$-version.

\subsection{Five Rebuttal Types}

Viewing argumentation schemes as "a kind of generalized rules of inference [...] express[ing] that, given certain [accepted] premises, a specific conclusion can be drawn" (Verheij 2003, 167), Verheij observes that schemes are often "defeasible, concrete and contingently valid, i.e., valid in certain contexts or under certain circumstances" (ibid.). Since a CQ's purpose is "to question the dialectical relevance of an argument based on the scheme" (ibid., 173), he views rebuttals as functional elements that "involve conditions of exception for the argument" $(2006,194)$.

Verheij thus distinguishes rebuttals as per what one may argue against:

(11) Five elements one may argue against

1. The data, D

2. The claim, $\mathrm{C}$

3. The warrant, $\mathrm{W}$

4. The associated conditional 'if $\mathrm{D}$, then $\mathrm{C}$ ' expressing the bridge from $\mathrm{D}$ to C

5. The associated conditional 'if $\mathrm{W}$, then if $\mathrm{D}$, then $\mathrm{C}$ ' expressing the bridge between $\mathrm{W}$ and 'if $\mathrm{D}$, then $\mathrm{C}$ '

From this, one straightforwardly obtains five types of rebuttal (Fig. 2). 

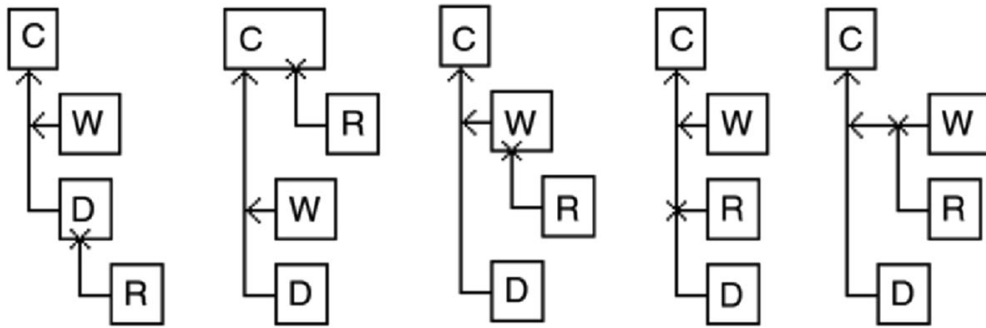

Fig. 2 Five types of rebuttals (Verheij 2006, 195)

The arrows in Fig. 2 denote the associated conditional, itself representing the linguistic realization of what Verheij calls 'primitive implication' (ibid., 178, esp. note 4). Symbolized as ' $\sim>$ ', the truth of this conditional's antecedent provides a reason for, and thus supports, the consequent exclusively in virtue of a premise's substance (rather than its logical form). 'D >C' thus expresses a "relation between $\mathrm{D}$ and $\mathrm{C}$ that is not captured by the truth values of $\mathrm{D}$ and $\mathrm{C}$ alone" (ibid., 178). Unlike the "notorious material conditional of standard logic" (ibid., 178), the associated conditional "only validates [the formally valid inference] Modus ponens" (ibid., 187). The truth of $\sim>$ does therefore not follow from the falsity of its antecedent, nor does the truth of $\sim>$ require a true antecedent. ${ }^{17}$ For instance, granted that 'Harry was born in Bermuda $\sim>$ Harry is a British subject' is true, the associated conditional remains true even if its antecedent is defeated, i.e., if it turns out that Harry was not born in Bermuda.

Marked in Fig. 2 with lines ending in an ' $x$ ', moreover, type-1, 2, 3 rebuttals attack respectively the data, the claim, and the warrant, whereas type- 4 and type-5 rebuttals attack the modus ponens inference. A rebuttal of type-5, for instance, targets: 'If $\mathrm{W}$, then if $\mathrm{D}$, then $\mathrm{C}$ ', in form: $\mathrm{W} \sim>(\mathrm{D} \sim>C$ ) (ibid., 191). Similarly, a type-4 rebuttal targets $\mathrm{D} \sim \mathrm{C}$.

Toulmin and Verheij differ in how they treat the warrant. To Verheij (ibid., 192), a warrant justifies the connection between $\mathrm{D}$ and $\mathrm{C}$ (justification interpretation); to Toulmin $(1958,91)$, by contrast, a warrant functions as a "bridge" and merely connects $\mathrm{D}$ and $\mathrm{C}$ (connection interpretation). ${ }^{18}$ As the item that shoulders the justification, Verheij's warrant thus plays the functional role that Toulmin assigns to the backing. Both authors chose different formulations: Verheij's warrant appears in a rule statement; Toulmin's backing appears in a fact statement (see Sects. 4.3, 4.4).

\footnotetext{
17 We thank an anonymous reviewer for clarifying the nuances of this construction, which earlier versions of this paper had misrepresented severely.

18 Remaining somewhat vague as to his own preferred interpretation, Toulmin (2003, 91; italics added) states that warrants "can act as bridges, and authorize the sort of step to which our particular argument commits us. These may normally be written very briefly (in the form 'If D, then C') [...]." The term 'authorize' may suggest that the warrant justifies the D-to-C transition. Yet the bulk of Toulmin's writing instead indicates that he adopts the comparatively weaker connection-interpretation.
} 


\subsection{From Five Types to Three}

Type- 1 and type- 2 rebuttals feature distinct contents that attack the data, respectively the claim. Though type-3, 4, and 5 rebuttals are structurally distinct, each type directly or indirectly attacks the modus ponens relation. For instance, the type- 3 rebuttal 'A man born in Bermuda is normally French' targets 'A man born in Bermuda is normally a British subject' (W). The type-4 rebuttal 'Harry has become a naturalized American' targets the (saturated) associated conditional 'if $\mathrm{D}$, then $\mathrm{C}$ ', thus targeting the connection between 'Harry was born in Bermuda' (D) and 'Harry is a British subject' (C). Finally, the type-5 rebuttal 'Harry's parents are aliens' targets 'A man born in Bermuda will generally be a British subject' (W) by providing a reason against applying $\mathrm{W}$.

Both a type-3 and a type-5 rebuttal thus attack the connection between D and C. A type-4 rebuttal attacks 'If $\mathrm{D}$, then $\mathrm{C}$ ' directly, and a type-5 or type-3 rebuttal attacks the justification of 'If $\mathrm{D}$, then $\mathrm{C}$ ' directly, and hence attacks 'If $\mathrm{D}$, then $\mathrm{C}$ ' indirectly. Therefore, type- 3 and type- 5 rebuttals are structurally distinct but functionally equivalent variants of a type- 4 rebuttal.

Verheij models an argument that transfers an evaluation from accepted premises (marked with '!') to claims about issues (marked with '?') (Fig. 3) as a two-step modus ponens derivation (Fig. 4). This model includes, first, a justification "from the warrant statement $[\ldots]$ to the arrow representing the associated conditional, that if Harry was born in Bermuda, he is a British subject"-thus from ' $\mathrm{W}, \mathrm{W} \sim>(\mathrm{D} \sim \mathrm{C})$ ' to ' $\mathrm{D} \sim>\mathrm{C}$ '. Second, it includes a justification from data to claim-thus from ' $\mathrm{D}$, $\mathrm{D} \sim>C$ ' to ' $\mathrm{C}$ '. (Hence, attacking ' $\mathrm{W}$ ' and attacking ' $\mathrm{W} \sim>(\mathrm{D} \sim>C)$ ' are two options of attacking D >C.) Finally, in 'If W, then if D, then C' (type-5), the 'if W'-part specifies 'If $\mathrm{D}$, then $\mathrm{C}$ ' (type-4) by providing a condition under which 'If $\mathrm{D}$, then $\mathrm{C}$ ' holds.

One can thus specify 'If $\mathrm{D}$, then $\mathrm{C}$ ' either to 'If $\mathrm{W}$, then if $\mathrm{D}$, then $\mathrm{C}$ ' or to 'If not $\mathrm{W}$, then if $\mathrm{D}$, then $\mathrm{C}$ ', which therefore makes type-5 a functional specification of type-4. By further integrating this fivefold typology, one retains three types, such that a type- 3 and a type- 5 rebuttal are both functional specifications of a type- 4

\section{? Harry is a British subject \\ ! A man born in Bermuda will generally be a British subject \\ Harry was born in Bermuda}

Fig. 3 Data, claim and warrant-model (Verheij 2006, 191)

Fig. 4 Two-step modus ponens derivation (Verheij 2006, 192)
W. $\mathrm{W} \sim(\mathrm{D} \sim \mathrm{C})$.

D.

$$
\mathrm{D} \sim \mathrm{C} \text {. }
$$

C. 
Fig. 5 Three kinds of attacks, leading to three kinds of CQs

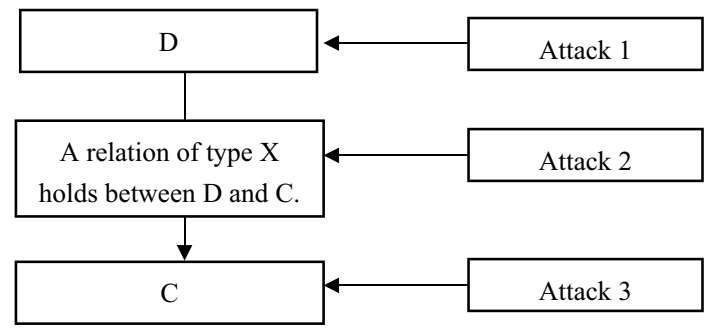

rebuttal. The CQs associated to type-3 and type-5 rebuttals should therefore be subCQs to those for a type-4 rebuttal (see below).

This allows our own CQ-list to use the three-role version, where one attacks arguments on their premises, inferences, or conclusions.

\section{A Complete CQ-List}

\subsection{Premise, Inference, and Conclusion Attacks}

A CQ-list's primary purpose being that of enabling a systematic argument evaluation, a complete evaluation requires a (preferably short) finite CQ-list. ${ }^{19}$ Although analysts are free to ask CQs in any order, the specific order we propose lets us develop a scheme's CQs step-by-step, level-by-level, starting at the meta-level. This list is meta-level complete insofar as sub-CQs arise only at the theoretical or applied level. (This is similar to how Pragma-dialecticians arrange argumentative patterns (van Eemeren 2016, 2017) and to how Macagno, Walton and Tindale (2017) detail analogical arguments via inferential structures and defeasibility conditions.)

Restricted to an attack's three targets-premises, inference, conclusion-we retain the following components of Toulmin's model, here combing a logical with a substantive account of argument schemes according to modus ponens (Fig. 5). Attack-1 and attack-2 both imply an attack-3 because by attacking D, or the D-C relation, one attacks $\mathrm{C}$ indirectly, without offering a direct counter-reason. The three kinds yield a straightforward meta-level CQ-list: CQ-1 for attack 1, CQ-2 for attack 2, and CQ-3 for the direct attack 3. As will become clear soon, one should first ask CQ-1, followed by CQ-2, and next CQ-3.

\footnotetext{
${ }^{19}$ When treated instead as pointers to counterarguments (see Sect. 5.1), CQs would be assertives rather than interrogatives. For the same premise, moreover, the number of pointers can exceed the number of necessary CQs. In case of ' $a$ is an honest source', for instance, the necessary CQ simply is: 'Is $a$ in fact an honest source?' Yet multiple pointers can direct us towards counter-arguments. For instance: 'Liars are prone to dishonesty', or 'An ill-hearted person can be a dishonest source', 'As can an interest-conflicted person', etc. Hence, if one saw the main purpose of a CQ-list in generating these pointers, then one could readily associate several pointers to a single CQ. To avoid such multiplicity, we define our CQs extensionally (in Sects. 6.2, 6.3).
} 


\subsection{Towards a Complete Meta-Level CQ-List}

We first present the basic CQs and their evaluative answers, adding further CQs and sub-CQs in Sect. 6.3. Our CQs all use the term 'correct'; of course, one may substitute with '(rhetorically) acceptable', '(logically or factually) true', '(epistemologically or doxastically) plausible', etc.

\section{CQ-1. Are the data correct?}

This CQ evaluates the content of the data element.

\section{$C Q$-2. Is 'If $D$, then $C$ ' correct?}

Once saturated, this conditional expresses the focal substantive relation. The corresponding CQ, then, is: "Does the (content of the) 'D therefore C'-relation hold?"

Evaluating the D-to-C-relation regularly requires more information than arguers offer or analysts can access readily. For instance, in "[a]s Daniel is an American [...] he is sure to be concerned about the costs" (van Eemeren and Grootendorst 1992, 97), acceptability would transfer from data to claim, insofar as a symptomatic relation were to hold between Daniel being American and being inclined to care about the costs. Upon assuming that Daniel is American, however, one may nevertheless specify this relation in various ways: "Americans generally care (lots) about money" (ibid.), 'Young Americans care (lots) ...', or 'Male Americans ...', etc. Yet the right choice is not obvious. Absent information to the contrary, one should interpret D's predicate ("is American") as naming the intended category. For acceptability to transfer, then, this category must include D's subject (Daniel). Indeed, since argument evaluation presupposes that one can know the intended category, the first step is to determine it.

If D's intended category implies C's predicate necessarily, because D's subject necessarily belongs to the intended category, then D's subject implies C's predicate logically, and hence 'D implies C' holds. (One may interpret 'necessary implication' epistemically or ontically; regardless, 'knowing- $p$ ' entails ' $p$ ', but not vice versa.) By contrast, if D's intended category fails to imply C's predicate necessarily, then one must test whether D's subject belongs to the intended category's exception class. If so, then D's subject fails to imply C's predicate logically.

In this case, one arrives at the following sub-CQs: CQ-2.1 "What is the intended category of D's subject?" CQ-2.2 "What is the content of the substantive relation between D and C (represented by the 'if-then' conditional)?" CQ-2.3 "Is the relation between the intended category of D's subject and C's predicate claimed to hold necessarily?" Finally, if one answers CQ-2.3 negatively: CQ-2.4 "Does D's subject belong to the focal exception class?" In this way, CQ-2 narrowly examines only (the content of) the inference 'if $\mathrm{D}$, then $\mathrm{C}$ '.

For instance, instead of category membership - as in "Daniel is American"arguers may assert state of affairs such as "The weather is fine," and conclude: "let's go for a hike." Assume the weather is fine. The evaluation would proceed as follows: to the arguer, suppose, fine weather is but one among other enabling conditions such 
as "money in the bank," "time on one's hand," or "energy to spare," etc. (Where such conditions are negated, they express inference-exceptions.) Since the relation between the weather and the hike is contingent rather than necessary, evaluation thus proceeds with the above sub-CQ-2.1 to CQ-2.4. For contingent relations generally, one cannot fix all enabling conditions that count towards the arguer's intended category.

\section{CQ-3. Is the claim correct?}

Evaluating an argument's claim implies evaluating whether all relevant data have been considered fully. This makes CQ-3 broader than CQ-1 (correctness of data), and presupposes having specified the 'D-to- $C$ ' relation by answering CQ-2. If analysts can offer additional relevant data, $\mathrm{D}^{*}$, then further pro- or con-arguments relate to the claim. To evaluate them, and then compare the strength of pro- and con-arguments, one must iterate the evaluative process.

We have so far shown that our CQ-list applies specifically to the Harry-example, which cites a symptomatic relation between premise and claim. This leaves the relations of similarity and causality effectively untreated. Two anonymous reviewers therefore rightly expressed doubt that our CQ-list is general. For reasons of limited space, we can only offer an indirect response: one can regiment any argument scheme to the form: ' $x$ has property $F$, so $x$ has property $G$ ' (Hitchcock 2017, 296). It follows that all object-level arguments are meta-level sign arguments. Put differently, the symptomatic relation reduces both the similarity and the causality relation. Hence, if our model evaluates sign arguments completely, and we believe it does, then it evaluates any argument completely.

\subsection{Full Meta-Level CQ-List}

The full version of our CQ-list (including sub-CQs) is the following:

\section{CQ-1 Is D correct?}

- If not, or if no clear answer is forthcoming, then the evaluation process stops, resulting in a negative evaluation.

- If yes, then the evaluation process continues.

CQ-2.1 What is the intended category of D's subject?

- If no clear answer comes forth, the process stops with a negative evaluation.

- Otherwise, the evaluation continues.

$C Q-2.2$ What is the content of the 'D therefore C'-relation?

- If no clear answer comes forth, the process stops with a negative evaluation.

- Otherwise, the evaluation process continues. 
CQ-2.3 Does the relation between D's intended category and C's predicate hold necessarily?

- If yes, then the process stops with a positive evaluation.

- If not, or if no clear answer comes forth, then the evaluation continues.

CQ-2.4 Does D's subject belong to an exception-class of its intended category (as per $C Q-2.1)$ ?

- If yes, then the process stops with a negative evaluation.

- If not, then the process stops with a positive evaluation.

- If no clear answer comes forth, then the evaluation continues.

CQ-3.1 Can one offer additional relevant data (D*) besides D?

- If no clear answer comes forth, the process stops with a negative evaluation.

- If yes, then add these data, and return to CQ-1.

- If no, then the evaluation continues.

CQ-3.2 Are there other arguments against the claim $?^{20}$

- If yes, then evaluate these arguments (pros versus cons).

- If no, then the process stops with a positive evaluation.

The evaluation process stops if analysts find the argument good, or bad; or if lack of information makes this impossible (e.g., for CQ-1, one may not know whether $\mathrm{D}$ is correct). Having thus defined our CQs extensionally, we can proceed to apply them. $^{21}$

\subsection{Applying the CQs}

Our CQ-list assumes that D is explicit. In a realistic argumentative context, this is implausible. The Harry-example, for instance, might read: 'A man born in Bermuda will be a British subject, so Harry is a British subject'. This leaves D implicit.

Generally, analysts must make choices when they specify implicit elements, and these specifications can easily differ in use value. For instance, Verheij $(2006,190)$ distinguishes three warrant-versions: (i) 'A man born in Bermuda will generally be a British subject'; (ii) 'If a person was born in Bermuda, then generally that person is a British subject'; (iii) 'If Harry was born in Bermuda, then generally he is a British subject.' Verheij (ibid., 190f.) treats (i) as the warrant's ordinary language

\footnotetext{
${ }^{20} \mathrm{CQ}-3.1$ sits before CQ-3.2, because the reverse order may require asking CQ-3.2 twice, namely once again if the answer to CQ-3.1 is positive. One should consider CQ-3.1 before CQ-3.2 also because the answer "fewer than all relevant data were considered" normally amounts to a reason against the claim.

21 Walton and Sartor $(2013,111)$ state that argument evaluation "needs to take into account the attitudes of dialogue partners as well as normative models of dialogue and communicative activity types, in particular social and cultural settings." Of course, such considerations may influence one's evaluative criteria, as well as the answers to the CQs themselves. Yet they will not determine a meta-level CQ-list's content.
} 


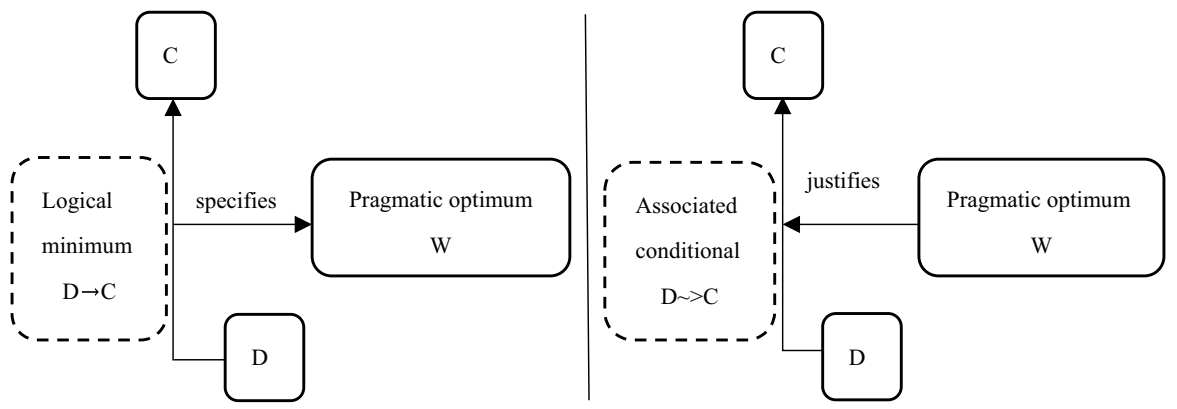

Fig. 6 Two D-W-C models

Fig. 7 D-W-B-C model

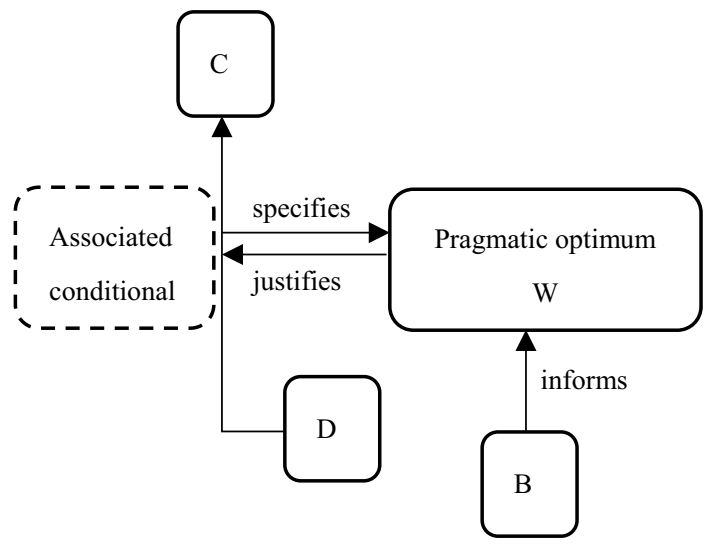

expression, (ii) as "the formal explication of the bridge-like connection," and (iii) as "the associated conditional" expressing that a particular D implies a particular C.

Given the pragmatic optimum versus logical minimum-distinction (van Eemeren and Grootendorst 1992, 98f.), (iii) thus expresses the logical minimum, (i) expresses the pragmatic optimum, and (ii) can be a pragmatic optimum in at least some contexts. $^{22}$ To Verheij, the pragmatic optimum justifies the associated conditional formally, while Pragma-dialecticians proceed in the opposite direction: the pragmatic optimum specifies the logical minimum. In specifying the logical minimum to the pragmatic optimum, then, one invariably justifies how one arrives at the pragmatic optimum in a specific context. This entails that one obtains two D-W-C models (Fig. 6).

\footnotetext{
${ }^{22}$ The logical minimum is "a modus ponens-like inference from premises to a conclusion" (van Eemeren and Grootendorst 1992,97). The pragmatic optimum requires that arguers make the logical minimum "as informative as possible without ascribing unwarranted commitments to the speaker and [while] formulating it in a colloquial way that fits in with the rest of the argumentative discourse" (ibid., 64).
} 
According to modus ponens, the logical minimum is valid even if D is false. Similarly, when D is false, the associated conditional D >C can be correct, as long as D supports C. Per CQ-1, instead, if D is false, then argument evaluation stops with a negative result. Further, a D-to-C transition differs from a B-to-C transition: the first justifies the transition, while the second transforms this justification according to a context (see Sect. 4.3). Thus, in Fig. 7, the backing informs the pragmatic optimum. This we can articulate further in Fig. 8.

Given a context, one may specify a doxastic fact-formulation into a doxastic ruleformulation (see the W-to-B transformation; Sect. 4.3). As an instance of Fig. 8, then, see Fig. 9, which connects both doxastic elements (using a line without arrowhead) to represent that information is neither added nor deleted.

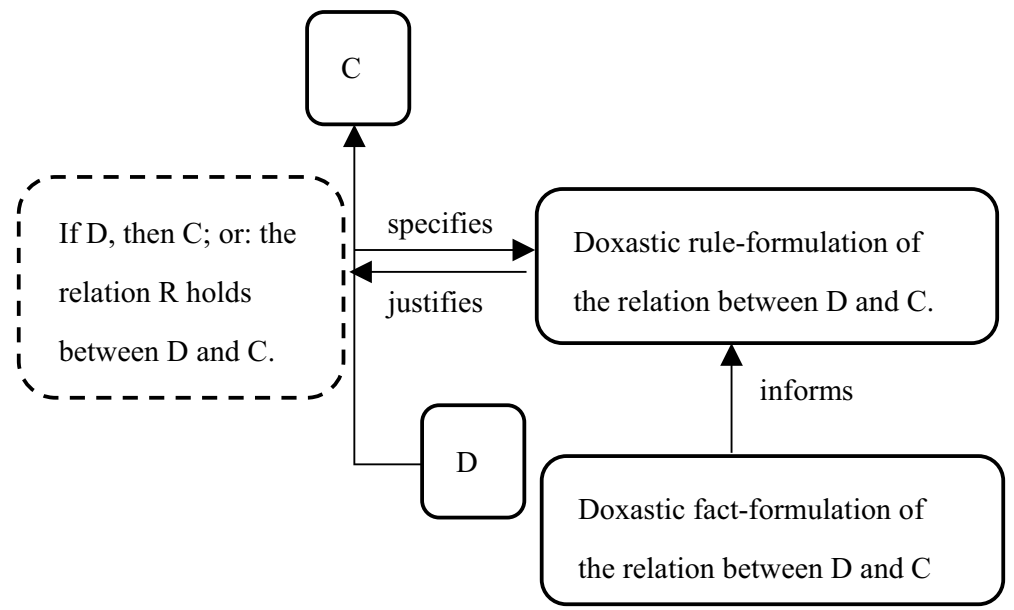

Fig. 8 Argument components

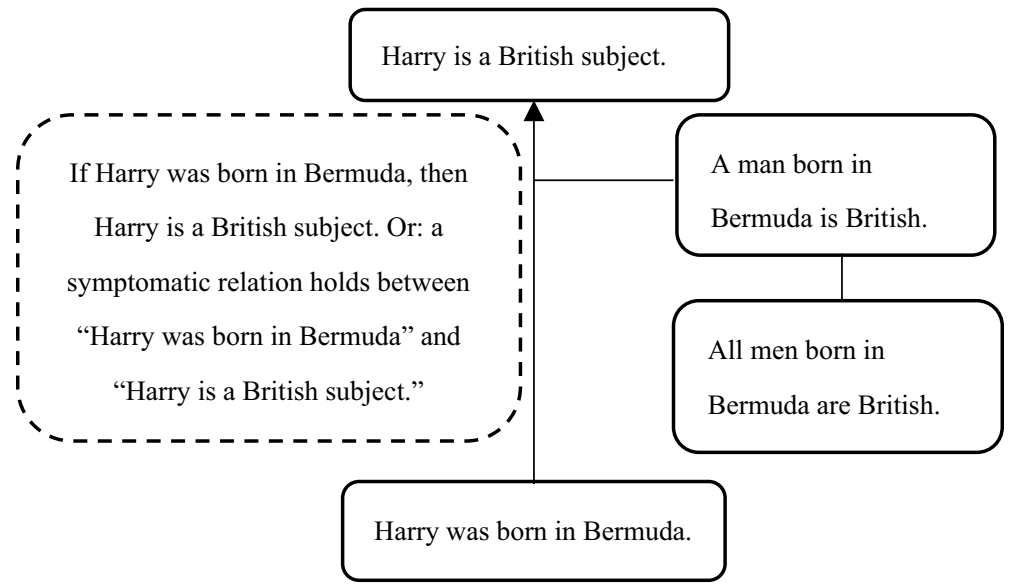

Fig. 9 The components of Toulmin's Harry-example 
Table 1 Possible argumentcomponent combinations

$\begin{array}{ll}\text { (1) } & \text { D, so C } \\ \text { (2) } & \text { W, so C } \\ (3) & \text { B, so C } \\ \text { (4) } & \text { D, W, so C } \\ (5) & \text { D, B, so C } \\ (6) & \text { W, B, so C } \\ \text { (7) } & \text { D, W, B, so C }\end{array}$

\subsection{Standardization}

Before concluding, we review the seven possible combinations of argument components that may appear in natural language (Table 1).

By rearranging and/or supplementing these components, one can standardize (1)-(7) to the form 'D, W, so C'. In fact, 'D, so C' already suffices to apply our CQlist. The following illustrates this with the Harry-example:

1. D, so $C$ ("Harry was born in Bermuda. So, Harry is a British subject.") To this form, the CQ-list is already applicable.

2. W, so $C$ ("A man born in Bermuda is a British subject. So, Harry is a British subject.") To obtain a data element, one must transform W into a doxastic factformulation. The warrant's ontological formulation is the original backing: 'All men born in Bermuda are British subjects'. Considering this backing as a dataelement, one can treat ' $\mathrm{W}$, so C' as (1). ${ }^{23}$

3. B, so $C$ ("All men born in Bermuda are British subjects, so Harry is a British subject.") One may treat (3) as 'D, so C'—which puts one back at (1)—or may transform B into $\mathrm{W}-$ which puts one back at (2).

4. $D, W$, so $C$ ("Harry was born in Bermuda, and a man born in Bermuda is a British subject; so Harry is a British subject.") It is easy to distinguish D and W; one can apply 'D, so C' as per (1), or ' $\mathrm{W}$, so C' as per (2).

5. $D$, $B$, so $C$ ("Harry was born in Bermuda, and all men born in Bermuda are British subjects; so Harry is a British subject.”) Both B and D are fact-formulations. Without further assumptions, distinguishing their roles proves challenging. After all, B's doxastic rule-formulation can represent the relation between $\mathrm{D}$ and $\mathrm{C}$, but D's doxastic rule-formulation cannot represent the relation between $\mathrm{B}$ and $\mathrm{C}$. Of course, one may assume some fact-formulation as $\mathrm{B}$, and then test whether it represents the relation between the other fact-formulation and $\mathrm{C}$. If so, then one should treat it as B, otherwise as D. At last, then, one can distinguish D and B, and thus apply 'D, so C' as per (1) or, respectively, 'B, so C' as per (3).

\footnotetext{
${ }^{23}$ The warrant connects C to D (rather than to B). Since D and B both constitute a fact-formulation, our model applies insofar as a fact-formulation serves as a premise. Thus, one need not formulate the original data, but can use the backing as a new D, itself transformed from $\mathrm{W}$. Where the original $\mathrm{D}$ is unknown, the transformation reflects an evaluation based on additional known information.
} 
When evaluating the form ' $\mathrm{D}, \mathrm{B}$, so C' - e.g., "Harry was born in Bermuda, and all men born in Bermuda are British subjects; so Harry is a British subject"-one cannot distinguish the premises' roles immediately, because both premises state facts. One therefore needs something like the following test: the rule-formulation of "All men born in Bermuda are British subjects" is "A man born in Bermuda is a British subject." This reflects the relation between "Harry was born in Bermuda" and "Harry is a British subject." So B is: "All men born in Bermuda are British subjects." By contrast, the rule-formation of "Harry was born in Bermuda" is "If a man is Harry, then he was born in Bermuda." But this cannot suitably connect "All men born in Bermuda are British subjects" with "Harry is a British subject." Therefore, one cannot justify "Harry is a British subject" with "All men born in Bermuda are British subjects." It follows that "Harry was born in Bermuda" is not a B. ${ }^{24}$

6. $W, B$, so $C$ ("A man born in Bermuda is a British subject, and all men born in Bermuda are British subjects; so Harry is a British subject.") It is easy to distinguish $\mathrm{W}$ and $\mathrm{B}$; the first is a rule-formulation, the other is a fact-formulation. Hence, one can apply ' $\mathrm{W}$, so $\mathrm{C}$ ' as per (2), or 'B, so C' as per (3).

7. $D, W, B$, so $C$ ("Harry was born in Bermuda, and a man born in Bermuda is a British subject, and all men born in Bermuda are British subjects; so Harry is a British subject.") One can treat this form either as 'D, so C' as per (1), or as 'W, so C' as per (2), or as 'B, so C' as per (3).

Given argument components that correspond to D, W, B, C, then, the foregoing applies to any argument, and so facilitates a complete meta-level evaluation.

\section{Conclusion}

Treating ARGUMENT SCHEME as a logical concept, we have sought to capitalize on the distinction between an argument scheme's levels, separating an applied level, from a theoretical, and a meta-level. If this approach to evaluating natural language arguments completely does succeed, then this would be so because we proceeded from the outset at the meta-level. This showed that one can abstract all elements that a complete evaluation must address. Although this result is fully consistent with a logical account, we also saw why a substantive account must complement it, and how a specification of Toulmin's model can ground this hybrid account. Having applied our complete CQ-list so far only exemplarily, future research should relate our meta-level CQs to the applied level in order to

\footnotetext{
${ }^{24}$ We thank an anonymous reviewer for pointing out an alternative rule-formation for "Harry was born in Bermuda," namely "If every man born in Bermuda has a certain property, then Harry has it." This alternative rule-formulation can connect "All men born in Bermuda are British subjects" with "Harry is a British subject." However, it not only is a less natural formulation, but also involves a second-order generalization.
} 
obtain specific criteria for a given scheme. This should advance the construction of an exhaustive list of applied CQs.

Acknowledgements We thank Minghui Xiong, as well as two anonymous reviewers for this journal, for their extensive and at times painstakingly detailed comments, all of which served to improve previous versions of this paper. SY acknowledges support from the Major Program of the National Social Science Foundation of China (No. 14ZDB013).

Open Access This article is licensed under a Creative Commons Attribution 4.0 International License, which permits use, sharing, adaptation, distribution and reproduction in any medium or format, as long as you give appropriate credit to the original author(s) and the source, provide a link to the Creative Commons licence, and indicate if changes were made. The images or other third party material in this article are included in the article's Creative Commons licence, unless indicated otherwise in a credit line to the material. If material is not included in the article's Creative Commons licence and your intended use is not permitted by statutory regulation or exceeds the permitted use, you will need to obtain permission directly from the copyright holder. To view a copy of this licence, visit http://creativecommons.org/licen ses/by/4.0/.

\section{References}

Besnard, P., and A. Hunter. 2008. Elements of argumentation. Cambridge, MA: MIT Press.

Biro, J.I., and H. Siegel. 1992. Normativity, argumentation and a doxastic theory of fallacies. In Argumentation illuminated, ed. F.H. van Eemeren, R. Grootendorst, J.A. Blair, and C.A. Willard, 85-103. Amsterdam: Sic Sat.

Blair, J.A. 2001. Walton's argumentation schemes for presumptive reasoning: A critique and development. Argumentation 15: 365-379.

Blair, J.A. 2011. Groundwork in the theory of argumentation. New York: Springer.

Bondarenko, A., P. Dung, R. Kowalski, and F. Toni. 1997. An abstract, argumentation-theoretic approach to default reasoning. Artificial Intelligence 93: 63-101.

Bondy, P. 2010. Truth and argument evaluation. Informal Logic 30: 142-158.

Conley, T.M. 1990. Rhetoric in the European tradition. Chicago, IL: University of Chicago Press.

Daniel, S., and D. Nic. 2014. The deflationary theory of truth. In The Stanford Encyclopedia of Philosophy (Fall 2014 Edition), ed. Edward N. Zalta. https://plato.stanford.edu/archives/fall2014/ entries/truth-deflationary/. Accessed 18 Feb 2020.

Ennis, R. 1982. Identifying implicit assumptions. Synthese 51: 61-86.

Freeley, A.J., and D.L. Steinberg. 2009. Argumentation and debate: Critical thinking for reasoned decision making, 12th ed. Boston: Wadsworth Cengage Learning.

Freeman, J.B. 1985. Dialectical situations and argument analysis. Informal Logic 7: 151-162.

Freeman, J.B. 1991. Dialectics and the macrostructure of arguments: A theory of argument structure. Berlin and New York: Foris Publications.

Garssen, B. 1994. Recognizing argumentation schemes. In Studies in pragma-dialectics, ed. F.H. van Eemeren and R. Grootendorst, 105-111. Amsterdam: Sic Sat.

Garssen, B. 1997. Agumentatieschema's in Pragma-dialectisch Perspectief. Een Theoretisch en Empirisch Onderzoek [Argument Schemes from a pragma-dialectical Perspective: A Theoretical and Empirical Overview]. Dissertation. Amsterdam: IFOTT.

Garssen, B. 2001. Argument schemes. In Crucial concepts in argumentation theory, ed. F.H. van Eemeren, 81-99. Amsterdam: Amsterdam University Press.

Godden, D., and F. Zenker. 2018. A probabilistic analysis of argument cogency. Synthese 195: 1715-1740.

Goodnight, G.T. 1993. Legitimation inferences: An additional component for the Toulmin model. Informal Logic 15: 41-52.

Gough, J., and C. Tindale. 1985. 'Hidden' or 'missing' premises. Informal Logic 7: 99-106.

Govier, T. 2001. A practical study of argument, 5th ed. Belmont, CA: Wadsworth. (1st ed. 1985). 
Grennan, W. 1997. Informal logic: Issues and techniques. Montreal: McGill-Queen's University Press.

Hahn, U., and J. Hornikx. 2016. A normative framework for argument quality: Argumentation schemes with a Bayesian foundation. Synthese 193: 1833-1873.

Hastings, A.C. 1962. A reformulation of the modes of reasoning in argumentation. Dissertation. Northwestern University, Evanston, IL.

Hitchcock, D. 2003. Toulmin's warrants. In Anyone who has a view. Theoretical contributions to the study of argumentation, ed. F.H. van Eemeren, J.A. Blair, C.A. Willard, and A.F. Snoeck Henkemans, 69-82. Dordrecht: Kluwer.

Hitchcock, D. 2006. Good reasoning on the Toulmin model. In Arguing on the Toulmin model. New essays in argument analysis and evaluation, ed. D. Hitchcock and B. Verheij, 203-218. Netherlands: Springer.

Hitchcock, D. 2017. On reasoning and argument: Essays in Informal Logic and Critical Thinking. Berlin: Springer.

Hitchcock, D., and B. Verheij (eds.). 2006. Arguing on the Toulmin model. New essays in argument analysis and evaluation. Netherlands: Springer.

Hitchcock, D.L., and J.H.M. Wagemans. 2011. The pragma-dialectical account of argument schemes. In Keeping in touch with pragma-dialectics, ed. E.T. Feteris, B.J. Garssen, and A.F. Snoeck Henkemans, 185-205. Amsterdam: Benjamins.

Hoffmann, M. 2016. Reflective argumentation: A cognitive function of arguing. Argumentation 30: 365-397.

Hoffmann, M. 2018. The elusive notion of "argument quality". Argumentation 32: 213-240.

Johnson, R.H. 2000. Manifest rationality: A pragmatic theory of argument. Mahwah, NJ: Lawrence Erlbaum Associates.

Johnson, R.H., and J.A. Blair 1994. Logical self-defense (U.S. edition). New York: McGraw-Hill.

Kienpointner, M. 1992. Alltagslogik. Struktur und Funktion von Argumentationsmustern [Everyday Logic. Structure and Function of Argument Patterns]. Stuttgart-Bad Cannstatt: Frommann-Holzbog.

Lumer, C. 2011. Argument schemes-An epistemological approach. In Argumentation: Cognition and community. Proceedings of the 9th international conference of the Ontario Society for the Study of Argumentation (OSSA), ed. F. Zenker, 1-32. Windsor, ON (CD ROM). https://scholar.uwindsor.ca/ cgi/viewcontent.cgi?referer $=\&$ httpsredir $=1 \&$ article $=1016 \&$ context $=$ ossaarchive. Accessed 18 Feb 2020.

Macagno, F., D. Walton, and C. Tindale. 2017. Analogical arguments: Inferential structures and defeasibility conditions. Argumentation 31: 221-243.

Marraud, H. 2018. Arguments from ostension. Argumentation 32: 309-327.

Peczenik, A. 2009. On law and reason. Dordrecht: Springer.

Perelman, C., and L. Olbrechts-Tyteca. 1958. La nouvelle rhétorique. Traité de l'argumentation. Paris: Presses Universitaires de France. [Perelman, C., and Olbrechts-Tyteca, L. 1969. The New Rhetoric. A Treatise on Argumentation (trans: Wilkinson, J., and Weaver, P.). Notre Dame: University of Notre Dame Press].

Pinto, R.C. 1994. Logic, epistemology and argument appraisal. In New essays in informal logic, ed. R.H. Johnson and J.A. Blair, 116-124. Windsor, ON: Informal Logic.

Pollock, J.L. 1987. Defeasible reasoning. Cognitive Science 11: 481-518.

Pollock, J.L. 1995. Cognitive carpentry. A blueprint for how to build a person. Cambridge, MA: MIT Press.

Prakken, H. 2005. AI \& law, logic and argument schemes. Argumentation 19: 303-320.

Prakken, H. 2010. On the nature of argument schemes. In Dialectics, dialogue and argumentation. An examination of Douglas Walton's theories of reasoning and argument, ed. C.A. Reed and C. Tindale, 167-185. London: College Publications. http://www.cs.uu.nl/groups/IS/archive/henry/schem es10.pdf. Accessed 18 Feb 2020.

Rapp, C., and T. Wagner. 2013. On some Aristotelian sources of modern argumentation theory. Argumentation 27: 7-30.

Rigotti, E., and S. Greco Morasso. 2006. Topics: The argument generator. In Argumentation for financial communication, Argumentum eLearning module. www.argumentum.ch. Accessed 18 Feb 2020.

Rigotti, E., and S. Greco Morasso. 2009. Argumentation as object of interest and as social and cultural resource. In Argumentation and education: Theoretical foundations and practices, ed. A.N. PerretClermont and N. Müller-Mirza, 9-66. New York: Springer. 
Rigotti, E., and S. Greco Morasso. 2010. Comparing the argumentum model of topics to other contemporary approaches to argument schemes: The procedural and material components. Argumentation 24: 489-512.

Rubinelli, S. 2009. Ars Topica. The classical technique of constructing arguments from Aristotle to Cicero. Netherlands: Springer.

Schut, D., and J.H.M. Wagemans. 2014. Argumentatie en debat. Den Haag: Boom Lemma.

Tindale, C. 2007. Fallacies and argument appraisal. Cambridge: Cambridge University Press.

Toulmin, S. E. (2003; 1958). The uses of argument (Updated ed.). Cambridge: Cambridge University Press (1st ed., 1958).

Toulmin, S.E., R.D. Rieke, and A. Janik. 1984. An introduction to reasoning, 2nd ed. New York: Macmillan. (1st ed., 1978).

van Eemeren, F.H., and T. Kruiger. 1987. Identifying argumentation schemes. In Argumentation: Perspectives and approaches: Proceedings of the conference on argumentation 1986, ed. van Eemeren, F.H., T. Kruiger, R. Grootendorst, J.A. Blair, and C.A. Willard, 70-81. Dordrecht-Holland/Providence: Foris Publications. [reprinted in: F.H. van Eemeren (ed.), Reasonableness and effectiveness in argumentative discourse, 2015, pp. 703-712. Cham: Springer International Publishing AG.].

van Eemeren, F.H. 2016. Identifying argumentative patterns: A vital step in the development of pragmadialectics. Argumentation 30: 1-23.

van Eemeren, F.H. (ed.). 2017. Prototypical argumentative patterns. Exploring the relationship between argumentative discourse and institutional context. Amsterdam/Philadelphia: John Benjamins.

van Eemeren, F.H. 2018. Argumentation theory: A pragma-dialectical perspective. Cham: Springer International Publishing AG.

van Eemeren, F.H., B. Garssen, E.C.W. Krabbe, F. Snoek Henkemans, B. Verheij, and J.H.M. Wagemans. 2014. Handbook of argumentation theory. Dordrecht: Springer.

van Eemeren, F.H., and R. Grootendorst. 1992. Argumentation, communication, and fallacies. Hillsdale: Lawrence Erlbaum.

van Eemeren, F.H., and R. Grootendorst. 2004. A systematic theory of argumentation. The pragma-dialectical approach. Cambridge: Cambridge University Press.

van Rees, M.A. 2001. Review of Ralph H. Johnson (2000), Manifest rationality. A pragmatic theory of argument. Argumentation 15: 231-237.

Verheij, B. 2003. Dialectical argumentation with argumentation schemes: An approach to legal logic. Artificial Intelligence and Law 11: 167-195.

Verheij, B. 2006. Evaluating arguments based on Toulmin's scheme. In Arguing on the Toulmin model. New essays in argument analysis and evaluation, ed. D. Hitchcock and B. Verheij, 181-202. Netherlands: Springer.

Verheij, B. 2014. Arguments and their strength: Revisiting Pollock's anti-probabilistic starting points. In Computational models of argument. Proceedings of the COMMA 2014, ed. S. Parsons, N. Oren, C. Reed, and F. Cerutti, 433-444. Amsterdam: IOS Press. http://dx.doi.org/10.3233/978-1-61499 -436-7-433.

Vreeswijk, G. 1997. Abstract argumentation systems. Artificial Intelligence 90: 225-279.

Wagemans, J.H.M. 2016. Constructing a periodic table of arguments. In Argumentation, objectivity, and bias. Proceedings of the 11th international conference of the Ontario Society for the Study of Argumentation (OSSA), ed. P. Bondy and L. Benacquista, 1-12. Windsor, ON. http://scholar.uwindsor.ca/ ossaarchive/OSSA11/papersandcommentaries/106.

Wagemans, J.H.M. 2019. Four basic argument forms. Research in Language 17: 57-69.

Walton, D. 1996. Argumentation schemes for presumptive reasoning. Mahwah: Lawrence Erlbaum.

Walton, D. 2016. Some artificial intelligence tools for argument evaluation: An introduction. Argumentation 30: 317-340.

Walton, D., C. Reed, and F. Macagno. 2008. Argumentation schemes. Cambridge: Cambridge University Press.

Walton, D., and G. Sartor. 2013. Teleological justification of argumentation schemes. Argumentation 27: 111-142.

Walton, D., C. Tindale, and T. Gordon. 2014. Applying recent argumentation methods to some ancient examples of plausible reasoning. Argumentation 28: 85-119.

Yu, S., and F. Zenker. 2018. Peirce knew why abduction isn't IBE. A scheme and critical questions for abductive argument. Argumentation 32: 569-587.

Yu, S., and F. Zenker. 2019. A dialectical view on conduction: Reasons, warrants, and normal suasory inclinations. Informal Logic 39: 32-69. 
Zenker, F. 2009. Ceteris Paribus in conservative belief revision. Berlin: Peter Lang.

Zenker, F. 2018. Logic, reasoning, argumentation: Insights from the wild. Logic and Logical Philosophy 27: 421-451.

Publisher's Note Springer Nature remains neutral with regard to jurisdictional claims in published maps and institutional affiliations. 